\title{
Roles of pulmonary telocytes in airway epithelia to benefit experimental acute lung injury through production of telocyte-driven mediators and exosomes
}

\author{
Li Tang $\cdot$ Dongli Song $\cdot$ Ruixue Qi $\cdot$ Bijun Zhu \\ Xiangdong Wang (1)
}

Received: 14 June 2021 / Accepted: 11 October 2021

(C) The Author(s), under exclusive licence to Springer Nature B.V. 2021

\begin{abstract}
Background Telocytes (TCs) are experimentally evidenced as an alternative of cell therapies for organ tissue injury and repair. The aims of the present studies are to explore direct roles of TCs and the roles of TC-derived exosomes in support of experimental acute lung injury (ALI) in vivo or in vitro.

Materials and methods The roles of TCs in experimental ALI were firstly estimated. Phosphoinositide 3 -kinase (PI3K) p110 $\delta$ and $\alpha / \delta / \beta$ isoform inhibitors were used in study dynamic alterations of biobehaviors, and in expression of functional factors of TCs per se and TC-co-cultured airway epithelial cells during the activation with lipopolysaccharide (LPS).
\end{abstract}

Li Tang, Dongli Song and Ruixue Qi contributed equally to this work.

Supplementary Information The online version contains supplementary material available at https://doi. org/10.1007/s10565-021-09670-5.

L. Tang $\cdot$ D. Song $(\bowtie) \cdot$ R. Qi $\cdot$ B. Zhu $\cdot$ X. Wang $(\bowtie)$ Department of Pulmonary and Critical Care Medicine, Zhongshan Hospital; Institute for Clinical Science Shanghai Institute of Clinical Bioinformatics Shanghai Engineering Research for AI Technology for Cardiopulmonary Diseases Jinshan Hospital Centre for Tumor Diagnosis and Therapy, Fudan University Shanghai Medical College, Shanghai, China e-mail: songdongli37@126.com

X. Wang

e-mail: xdwang@fuccb.com
TC-driven exosomes were furthermore characterized for intercellular communication by which activated or non-activated TCs interacted with epithelia.

Results Our results showed that TCs mainly prevented from lung tissue edema and hemorrhage and decreased the levels of VEGF-A and MMP9 induced by LPS. Treatment with CAL101 (PI3K p110 inhibitor) and LY294002 (PI3K $\alpha / \delta / \beta$ inhibitor) could inhibit TC movement and differentiation and increase the number of dead TCs. The expression of Mtor, Hifl $\alpha$, Vegf-a, or Mmp9 mRNA increased in TCs challenged with LPS, while Mtor, Hifl $\alpha$, and Vegf-a even more increased after adding CAL101 or Mtor after adding LY. The rate of epithelial cell proliferation was higher in co-culture of human bronchial epithelial (HBE) and TCs than that in HBE alone under conditions with or without LPS challenge or when cells were treated with LPS and CAL101 or LY294002. The levels of mTOR, HIF1 $\alpha$, or VEGF$A$ significantly increased in mono-cultured or cocultured cells, challenged with LPS as compared with those with vehicle. LPS-pretreated TC-derived exosomes upregulated the expression of AKT, p-AKT, HIF1 $\alpha$, and VEGF-A protein of HBE.

Conclusion The present study demonstrated that intraperitoneal administration of TCs ameliorated the severity of lung tissue edema accompanied by elevated expression of VEGF-A. TCs could nourish airway epithelial cells through nutrients produced from TCs, increasing epithelial cell proliferation, and differentiation as well as cell sensitivity to LPS 
challenge and PI3K p110 $\delta$ and $\alpha / \delta / \beta$ inhibitors, partially through exosomes released from TCs.

Keywords Acute lung injury · Telocytes · Exosomes $\cdot$ Phosphoinositide 3-kinase $\cdot$ Airway epithelial cells

$\begin{array}{ll}\text { Abbreviations } \\ \text { ANOVA } & \text { one-way analysis of variance. } \\ \text { ALI } & \text { Acute lung injury } \\ \text { ARDS } & \text { Acute respiratory distress syndrome } \\ \text { BALF } & \text { bronchoalveolar lavage fluid. } \\ \text { CCK-8 } & \text { Cell Counting Kit-8. } \\ \text { DMEM/12 } & \begin{array}{l}\text { Dulbecco's modified Eagle's medium/ } \\ \text { F12. }\end{array} \\ \text { ELISA } & \text { enzyme-linked immunosorbent assay. } \\ \text { HBE } & \text { Human bronchial epithelial } \\ \text { HE } & \text { hematoxylin-eosin. } \\ \text { HIF } & \text { hypoxia-inducible factor. } \\ \text { LPS } & \text { lipopolysaccharide. } \\ \text { MMP } & \text { matrix metalloproteinase. } \\ \text { MSCs } & \text { mesenchymal stem cells. } \\ \text { mTOR } & \text { mammalian target of rapamycin. } \\ \text { PI3K } & \text { phosphoinositide 3-kinase. } \\ \text { SPSS } & \text { Statistical Package for the Social } \\ & \text { Sciences. } \\ \text { TCs } & \text { Telocytes } \\ \text { TEM } & \text { transmission electron microscopy. } \\ \text { Tps } & \text { telopodes. } \\ \text { VEGF } & \text { vascular endothelial growth factor }\end{array}$

\section{Introduction}

Acute lung injury (ALI) is an early phase of acute respiratory distress syndrome (ARDS), which is characterized by lung tissue inflammation, epithelial and vascular barrier dysfunction, alveolar injury, and dysfunction of oxygen exchange (Alm et al., 2010; Chen et al., 2010; Fang et al., 2012). ALI is considered the first and critical organ damage during the development of multiple organ dysfunction caused by many factors. For example, the occurrence of ALI was suggested to be one of the most important risks and a decisive factor of mortality in patients with COVID19 (Li et al., 2020a; Zhang et al., 2020). Human bronchial epithelial cells, as one of the main defense barrier cells of the respiratory system, are widely involved in the regulation of airway inflammatory and immune responses. Airway epithelial cells can act as the primary receptor of local challenges (e.g., pollutions, chemicals, toxins, and pathogens from the air), and as the initial activator to produce inflammatory mediators (e.g., chemokines and cytokines) and be damaged, leading to lung tissue injury and systemic inflammation (Wang et al., 2007). Airway epithelial cells as the key player contribute to ALI/ARDS via the Toll-like receptor pathway, induce reactive oxygen species levels, and cause imbalance between activity of protease and antiprotease. There are studies suggesting airway epithelial cell as a therapeutic target to cure ALI/ARDS, probably by transplantation of mesenchymal stem cells, development of target drugs, and local nutrition, although effects of those potentials are to be furthermore clarified.

Zhang et al. (2020) tried to transplant telocytes (TCs), mesenchymal stem cells (MSCs), or combination intraperitoneally, intratracheally, and systemically and found that co-transplantation of MSCs and TCs could relieve the inflammation and edema of experimental acute lung injury, induced by lipopolysaccharide (LPS). This study provided the evidence that implanted TCs and MSCs by intraperitoneal injection could increase MSC migration, proliferation, and movement through osteopontin or epidermal growth factor-dominant networks. TCs are a newly defined type of interstitial cells, with own-specific phenomes characterized by global analyses of genomic and proteomic profiles (Sun et al., 2014; Zheng et al., 2014a). TCs directly contact and interact with multiple cells through paracrine small molecules released from telopodes (Tps) which are cellular extensions about 20-200 nm wide and $100 \mu \mathrm{m}$ length (Wollheim, 2016; Aleksandrovych et al., 2019; Faussone-Pellegrini \& Gherghiceanu 2016; Wang \& Cretoiu, 2016). TCs and stem cells could support epithelial cells directly through those Tps under the epithelium of the bronchioles and at the junction of the bronchoalveolar, to promote lung tissue development and regeneration and to maintain the integrity of vascular basement membrane (Popescu et al., 2011; Zheng et al., 2013).

Mammals have eight phosphoinositide 3-kinase (PI3K) subtypes, which are classified into Class I, Class II, and Class III. There are four class I PI3K catalytic subunits in mammals, and they are subdivided into class IA (p110 $\alpha, \mathrm{p} 110 \beta$, and $\mathrm{p} 110 \delta)$ and class IB enzymes (p110 $\gamma$ ) based on the differences 
in regulatory subunits (Bilanges et al., 2019). LPS can activate the $\mathrm{PI} 3 \mathrm{~K} /$ protein kinase $\mathrm{B}$ (Akt) pathway through Toll-like receptor 4 in vitro and directly induce collagen secretion in mouse lung fibroblasts (He et al., 2009). Inhibition of PI3K- $\gamma$ attenuates the pathological response induced by LPS by modulating inhibitory $\kappa \mathrm{B} \alpha / \mathrm{NF}-\kappa \mathrm{B}$ and innate immunity (Kim et al., 2012). LY (LY294002, PI3K $\alpha / \delta / \beta$ inhibitor) blocks the PI3K/Akt signaling pathway and can affect the pulmonary edema and microvascular permeability of LPS-induced ALI mouse models (Ding et al., 2020). Our previous research results show that PI3K isoform inhibitors $\mathrm{PI} 3 \mathrm{~K} \alpha / \delta / \beta$, PI $3 \mathrm{~K} /$ mammalian target of rapamycin (mTOR), and p1108 subtype is involved in the proliferation of TCs or TCs treated with TGF $\beta 1$. Among them, $\mathrm{PI} 3 \mathrm{~K} \alpha / \delta / \beta$ is more sensitive to the regulation of TC proliferation (Song et al., 2020).

The aims of the present studies are to explore direct roles of TCs in support of experimental ALI induced by LPS after intraperitoneal or intratracheal transplantation, respectively, as compared with other interstitial cells like fibroblasts. We investigated roles of PI3K p1 $10 \delta$ and $\alpha / \delta / \beta$ isoforms in dynamic alterations of bio-behaviors, and in expression of functional factors of TCs per se and TC-co-cultured airway epithelial cells (e.g., mTOR, vascular endothelial growth factor (VEGF)-A, hypoxia-inducible factor (HIF) $1 \alpha$, and matrix metalloproteinase (MMP)9) during the activation with LPS. We furthermore addressed potential mechanisms by which activated or nonactivated TCs interacted with epithelia directly or indirectly. We characterized TC-driven exosomes and studied potential mechanisms of exosomes for intercellular communication.

\section{Methods}

\section{Animals}

SPF grade C57BL/6 mice, 6-8 weeks old, male, weighing 20-25 g, were obtained from the Animal Center of Zhongshan Hospital, Fudan University. The animal experiment has been approved by the Animal Ethics Committee of Zhongshan Hospital of Fudan University (SCXK(Hu)2012-0002). The mice were randomly allocated into four groups, including animals pretreated and challenged with vehicle, pretreated with vehicle and challenged with lipopolysaccharide (LPS), pretreated with TCs and challenged with LPS, or pretreated with L929 cells (fibroblasts) and challenged with LPS as a non-specific cell control ( $n=4-6 /$ group). Mice were anesthetized with pentobarbital sodium (200-250 $\mu \mathrm{L} \quad 0.3 \%$ sodium pentobarbital solution/mouse) and pretreated with TCs, or L929 cells at $\times 10^{6}$ intraperitoneally. ALI was induced by the tracheal intubation of LPS purchased from Sigma-Aldrich, St. Louis, USA, at $5 \mathrm{mg} / \mathrm{kg}$ body weight $24 \mathrm{~h}$ after pretreatment with cells.

\section{Cell lines and cell culture}

The mouse-derived lung TCs were purified from BALB/c mice and transfected with SV40 large and small $\mathrm{T}$ antigen to establish telocyte cell line $\left(\mathrm{TCs}^{\mathrm{SV} 40}\right.$ ), as reported previously (Song et al., 2019a). The phenotypes and functions of $\mathrm{TCs}^{\mathrm{SV} 40}$ were evaluated in response to various challenges and treatments (Song et al., 2019b; Song et al., 2020). The culture medium of TCs ${ }^{\text {SV } 40}$ cells was Dulbecco's modified Eagle's medium supplemented with F12 (DMEM/F12, Hyclone, Boston, MA, USA), $10 \%$ fetal calf serum (FBS, GIBCO, Thermo Fisher Scientific, Inc., Waltham, MA, USA), penicillin at 100 units $/ \mathrm{mL}$, and streptomycin $0.1 \mathrm{mg} /$ $\mathrm{mL}$ (Sigma-Aldrich, St. Louis, USA). Cells were cultured in $5 \% \mathrm{CO}_{2}$ at $37^{\circ} \mathrm{C}$, passaged when the cell density reached $60-70 \%$ confluence, washed in PBS twice, digested with $0.25 \%$ trypsin, and harvested from the centrifugation at $400 \times g$ for $5 \mathrm{~min}$ for use. HBE135-E6E7 cells (HBE) were purchased from the Shanghai Institute for Biological Sciences (Shanghai, China, as a normal bronchial epithelial cell reference). HBE cells were cultured in RPMI 1640 (GIBCO) containing 10\% FBS and reached at an exponential growth rate for study. Cells were collected $24 \mathrm{~h}$ after LPS stimulation at $1 \mu \mathrm{g} / \mathrm{mL}$, with or without pretreatment with CAL (CAL101, PI3K p1108 inhibitor, Selleck, Houston, TX, USA) and LY (LY294002, PI3K $\alpha / \delta / \beta$ inhibitor, Selleck, USA) for $2 \mathrm{~h}$ (Figure S1C, D). In co-culture of TCs and HBE, TCs were located in the upper layer and HBE in the lower layer of the chamber (Figure S1E). Co-culture of TCs-exosomes (TCs-exo) and HBE: Exosomes were extracted from TCs after TCs were challenged with LPS and LY for $24 \mathrm{~h}$, and co-cultured with HBE cells in $1 \mathrm{~mL}$ of serum-free 
medium containing $6.5 \mu \mathrm{g}$ of exosomes for $24 \mathrm{~h}$ (Figure S1F).

\section{Morphological images}

Lung tissues of mice were collected for hematoxylin-eosin (HE) staining $24 \mathrm{~h}$ after the induction of ALI. Briefly, the trachea was intubated and the lungs were fixed with neutral formaldehyde at the pressure of $20 \mathrm{~cm} \mathrm{H}_{2} \mathrm{O}$, in order to maintain the alveolar structure, as reported (Jansson et al., 2006). Lung tissues were fixed at formaldehyde, embedded in paraffin, sectioned at 5-8 $\mu \mathrm{m}$, stained with HE, and observed under a light microscope. Acute lung inflammation and damage were scored using histological analysis according to the following scoring criteria. (Supplemental Table 1).

Ultrastructure of TCs in the lung tissue was investigated using transmission electron microscopy (TEM) after the tissue was fixed with $2.5 \%$ glutaraldehyde solution and sectioned into small pieces at $1 \mathrm{~mm}^{3}$ and immersed in $2.5 \%$. Morphological analysis of exosomes was performed by TEM, after exosomes were dissolved in PBS, dropped into a copper grid coated with carbon, and then stained with $2 \%$ uranyl acetate. Sample were observed using a J Tecnai G2 F20 ST TEM.

Measurement of acute lung edema

Acute lung edema was measured using ratio of mouse lung wet/dry (W/D) weights. Briefly, the trachea was separated and ligated at 2-3 tracheal cartilage rings, before the chest cavity was opened. The trachea and lung were isolated from the surrounding tissues and left on an absorbent paper to dry liquid on the surface of the lung tissue. The lungs were weighed for wet weight and the dry weight was obtained after the lungs were dried at $60^{\circ} \mathrm{C}$ for $72 \mathrm{~h}$.

Measurement of systemic cytokines

Plasma levels of cytokines were analyzed with the enzyme-linked immunosorbent assay (ELISA). Blood was collected in an anticoagulation tube with ethylene diamine tetraacetic acid and plasma was centrifuged and frozen at $-80^{\circ} \mathrm{C}$ until use. Plasma levels of interleukin (IL)-10 and IL- $1 \beta$ were measured by IL- $1 \beta$ and IL-10 ELISA kit (RayBiotech, Atlanta, USA). In addition, bronchoalveolar lavage was performed with PBS $1 \mathrm{~mL}$ 3-4 times after the mice were sacrificed with overdose of anesthesia. Bronchoalveolar lavage fluid (BALF) was collected, and then, the supernatant and cells were isolated for measurement. Mouse BALF levels of VEGF-A were measured by a commercial VEGFA ELISA kit (RayBiotech).

\section{Measurement of cell proliferation}

TCs at $5 \times 10^{4} /$ well, $10^{5} /$ well, and $2 \times 10^{5} /$ well in the upper layer were co-cultured with $\mathrm{HBE}$ at $10^{5}$ /well for 24,48 , and $72 \mathrm{~h}$, respectively. Cell proliferation was detected using Cell Counting Kit-8 (CCK-8), after CCK8 was added to each well of 96-well plate at the ratio of 1:10 CCK8/medium. The plate was incubated for $2-4 \mathrm{~h}$ in dark and detected using the SPECTRAMAX M2 microplate reader (Molecular Devices, San Jose, USA) at the absorbance of $450 \mathrm{~nm}$.

\section{Dynamic measurements of phenotype}

Cell phenotype was measured with Cell-IQ (ChipMan Technologies, Tampere, Finland), which is equipped with a camera and a phase contrast microscope (Nikon CFI Achromat phase contrast objective) $(\times 10)$, to take pictures for analyses. Images were filmed at approximately 1-h intervals using an imaging software (McMaster Biophotonics Facility, Ontario, Canada). Total cell count and biological behaviors of cells, including cell morphology and cell movement, were analyzed as time-lapse data using the Cell-IQ platform equipped with a visual machine. The manual tracking plugin was created by Fabrice Cordelie'res (Institute Curie, Orsay, France). And the rates of cell proliferation, migration, differentiation, and death were analyzed (Song et al., 2020; Song et al., 2019).

Isolation and purification of exosomes

TCs were cultured to approximately $75 \%$ confluence, and then, DMEM/F12 medium containing serum was removed and replaced with serum-free medium (IMDM). Cells were collected and centrifuged at $300 \times g$ for $10 \mathrm{~min}$ and then $2000 \times g$ for $10 \mathrm{~min}$ (to remove dead cells), followed by an 
ultra-centrifugation at $10,000 \times g$ for $30 \mathrm{~min}$ (to remove debris). After then, exosomes were isolated and purified by an ultra-centrifugation at $100,000 \times g$ for $70 \mathrm{~min}$. The exosomes were stained with PKH26 and added to the confocal dish for $24 \mathrm{~h}$. After then, the dish was added with $10 \mu \mathrm{L}$ Hoechst 33,342 $(100 \times)$ (Thermo Fisher Scientific) staining solution, incubated at $37^{\circ} \mathrm{C}$ for $1 \mathrm{~h}$, and observed using an Olympus FV3000 Confocal Laser Scanning Microscope (DSS Image tech Pvt. Ltd, New Delhi, India).

RNA extraction, cDNA synthesis, and quantitative PCR(qPCR)

Cells were washed thrice with cold PBS, and total RNA was extracted using the Trizol (TRIzol RNA Isolation Reagents, Thermo Fisher Scientific Inc., MA, USA) method. One microgram of total RNA was synthesized for cDNA using PrimeScript ${ }^{\circledR}$ RT Reagent Kit with gDNA Eraser (Takara Bio Inc., Shiga, Japan) which included PrimeScript RT Enzyme Mix. The SYBR Green Real-time PCR Mater Mix was used for quantitative PCR analysis (Takara Bio Inc., Shiga, Japan).

Detailed information of forward and reverse primers for qPCR is listed in Supplemental Table 2.

\section{Measurement proteins}

Total proteins of lung tissues were extracted from the supernatant after the tissue was lysed and centrifugated with radio immunoprecipitation assay (RIPA) and phenylmethanesulfonyl fluoride (PMSF), and from cultured cells or purified exosomes with ice-cold RIPA buffer containing halt protease and phosphatase inhibitors (Thermo Fisher Scientific). Protein concentration was measured by Bicinchoninic Acid (BCA) Protein Assay Reagent Kit (Thermo Fisher Scientific). Proteins from 10 to $20 \mu \mathrm{g}$ were separated by the gradients of $10 \%$ or $15 \%$ SDS-PAGE (Life Technologies) and transferred onto polyvinylidene fluoride (PVDF) membranes (Millipore, Germany). Then, the membranes with proteins were blocked with Trisbuffered saline with 5\% milk and Tween 20 (TBS-T) for $1 \mathrm{~h}$, and incubated with primary antibodies for $12 \mathrm{~h}$ at $4{ }^{\circ} \mathrm{C}$. After being washed in TBS-T thrice, membranes were incubated with HRP-conjugated secondary antibodies for $1.5 \mathrm{~h}$. Protein bands were developed using electrochemiluminescence (ECL) Western blotting substrate (Pierce, Rockford, IL, USA) under a Fusion FX7 device (Peqlab). Detailed information on primary antibodies and sources for Western blotting is listed in Supplemental Table 3.

\section{Statistical analysis}

The data are expressed as mean \pm standard error (SEM). Two-tailed unpaired Student's $t$ test was used for comparison between two groups, after the analysis of non-parametric one-way analysis of variance (ANOVA) (Kruskal-Wallis test) for multiple groups and additional Bonferroni post correction. All statistical analyses were performed using SPSS Statistics 20 (IBM, Chicago, USA). $p$ values less than 0.05 and 0.01 were considered statistically significant, respectively.

\section{Results}

Preventive effects of TCs in experimental ALI

Since the aim of the current study is to investigate the preventive effects of TCs in ALI, strategy of pretreatment with TCs or L929 cells for $24 \mathrm{~h}$ (Fig. 1A) was selected and validated in our previous studies (Wang et al., 2007), in order to allow transplanted cells to have enough time for seeding and recovering from manipulation. LPS induced lung tissue inflammation and lung injury was estimated. We found that LPS could induce alveolar wall rupture, alveolar cavity fusion, residual alveolar wall thickening, tissue edema, appearance of red blood cells in the alveoli, and leukocyte infiltration of monocytes in the alveolar wall, as compared with those challenged with vehicle (Fig. 1B). Lung histological analysis and images demonstrated that the severity of LPS-induced lung tissue injury was significantly lower in animals pretreated with TCs, as compared with those pretreated with vehicle or L929 cells, of which TCs mainly prevented from lung tissue edema and hemorrhage (Fig. 1C). Under the electron microscope, we noticed the existence of TCs with small cell bodies and long protrusions in lung tissue varied among groups. TCs were observed in LPS-induced lung tissue with or without pretreatment with cells (Fig. 1D). Plasma 

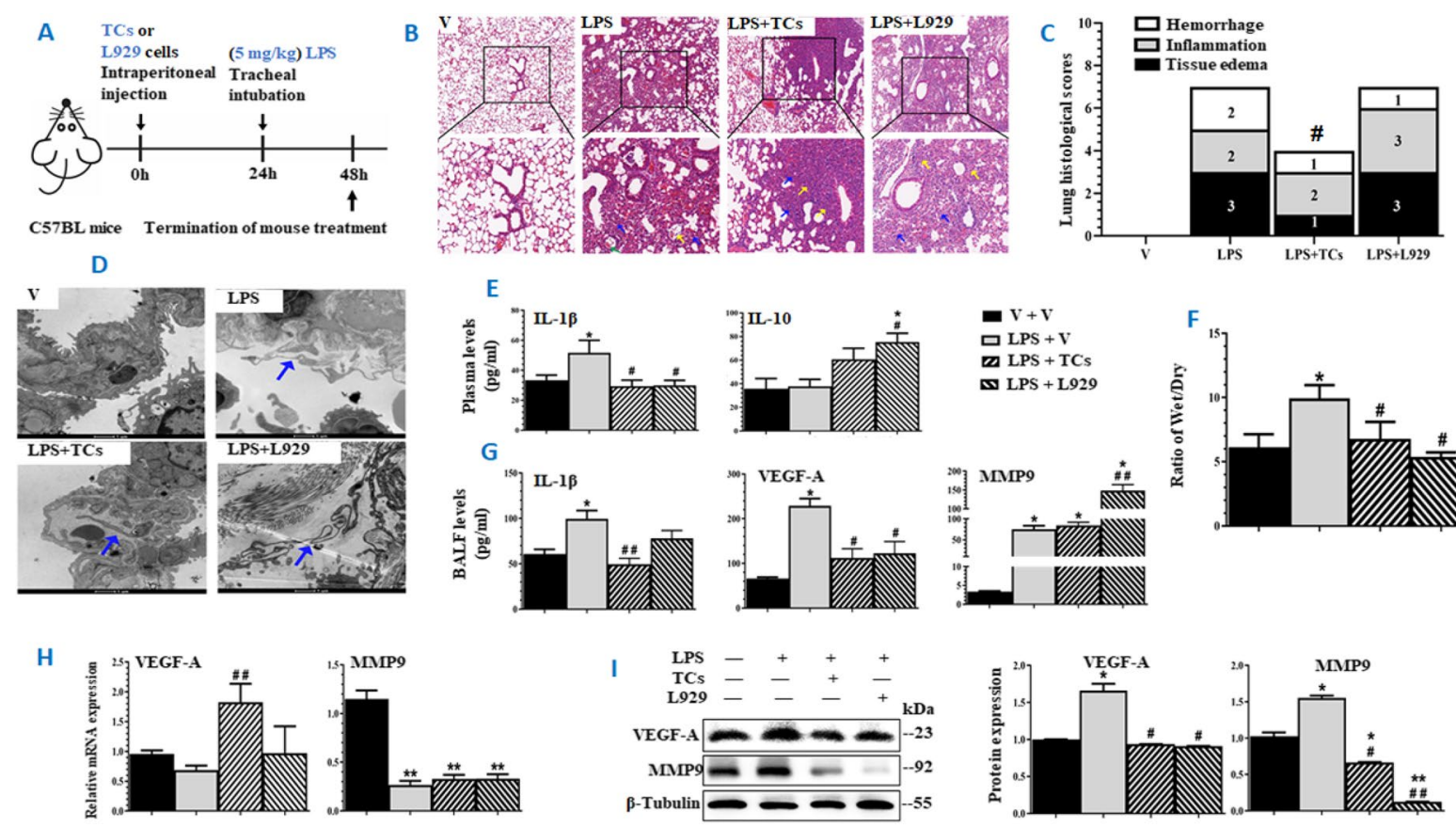

Fig. 1 Preventive roles of mouse lung-derived TCs in experimental acute lung injury induced by LPS. A Experimental workflow where mice were pretreated and challenged with vehicle $(\mathrm{V})$, pretreated with vehicle and challenged with LPS, pretreated with TCs and challenged with LPS (LPS + TCs), or pretreated with L929 cells (LPS + L929) ( $n=6 /$ group). Mice were pretreated with TCs or L929 cells at $10^{6}$ intraperitoneally $24 \mathrm{~h}$ prior to intratracheal administration of LPS. B Pathological changes of lung tissues harvested from mice and stained with $\mathrm{HE}$ at $\times 100$ (up panel) and $\times 200$ (low panel), respectively. The yellow arrows stand for the inflammatory cell infiltration, the blue arrows for the alveolar epithelial cell edema, and the green arrows for the local tissue hemorrhage.

levels of IL-1 $\beta$ and lung tissue wet/dry weight ratio significantly increased in LPS animals pretreated with vehicle (Fig. 1E, F, p < 0.05, vs other groups, respectively), rather than in animals with cells. Plasma levels of IL-10 were high in animals with cells, of which levels in L929 cell animals reached statistical significance. The increase of IL-10 level in animals treated with TCs was not significant. BALF levels of IL-1 $\beta$ and VEGF-A significantly increased in ALI animals with vehicle, which was prevented by pretreatment with cells (Fig. 1G). Intratracheal administration of LPS caused elevated levels of MMP9 in BALF fluid (Fig. 1G). mRNA expression of Vegf-a significantly increased in lung tissues harvested from LPS animals with TCs $(p<0.01)$, while $M m p 9$ decreased in LPS animals (Fig. 1H). Protein levels of VEGF-A or
C Pathological scores of lung tissue hemorrhage, inflammation, and tissue edema. D Paragraphs of lung ultrastructure by TEM $(10,000 \times)$. Green arrows stand for telopodes of TCs. E Plasma levels of IL-1 $\beta$ and 10. F Radio of Wet/dry lung weight. G BALF levels of IL-1 $\beta$, VEGF-A, and MMP 9. H mRNA expression of Vegf- $a$ and $M m p 9$ in lung tissues. I Protein expression of VEGF-A and MMP9. The left is the result of representative WB bands, and the right is the result of quantitative analysis of WB bands. * and ** stand for $p$ values less than 0.05 and 0.01 , as compared with animals pretreated and challenged with vehicle (V), while \# and \# \# stand for $p$ values less than 0.05 and 0.01 , as compared with animals pretreated with vehicle and challenged with LPS (LPS), respectively

MMP9 in lung tissues were higher in LPS animals with vehicle ( $p<0.05$, vs other groups, respectively), and MMP9 was lower in animals with cells (Fig. 1I).

\section{Roles of PI3K in TC responses to challenge}

The concentration of LPS at $1 \mu \mathrm{g} / \mathrm{mL}$ was selected from the screening of $0.01,0.10,1.00$, and $10.00 \mu \mathrm{g} /$ $\mathrm{mL}$ and the number of TCs alone and co-cultured TCs were defined from 5,10 , and $20 \times 10^{4}$ on basis of cell proliferation rate at 24,48 , and $72 \mathrm{~h}$, respectively (Figure S2B). Dynamic cell proliferation increased in LPS-challenged TCs, as compared with TCs with vehicle or treated with CAL or LY at different doses ( $p<0.05$; Fig. 2A). Treatment with CAL and LY could not inhibit TC movement (Fig. 2B) 

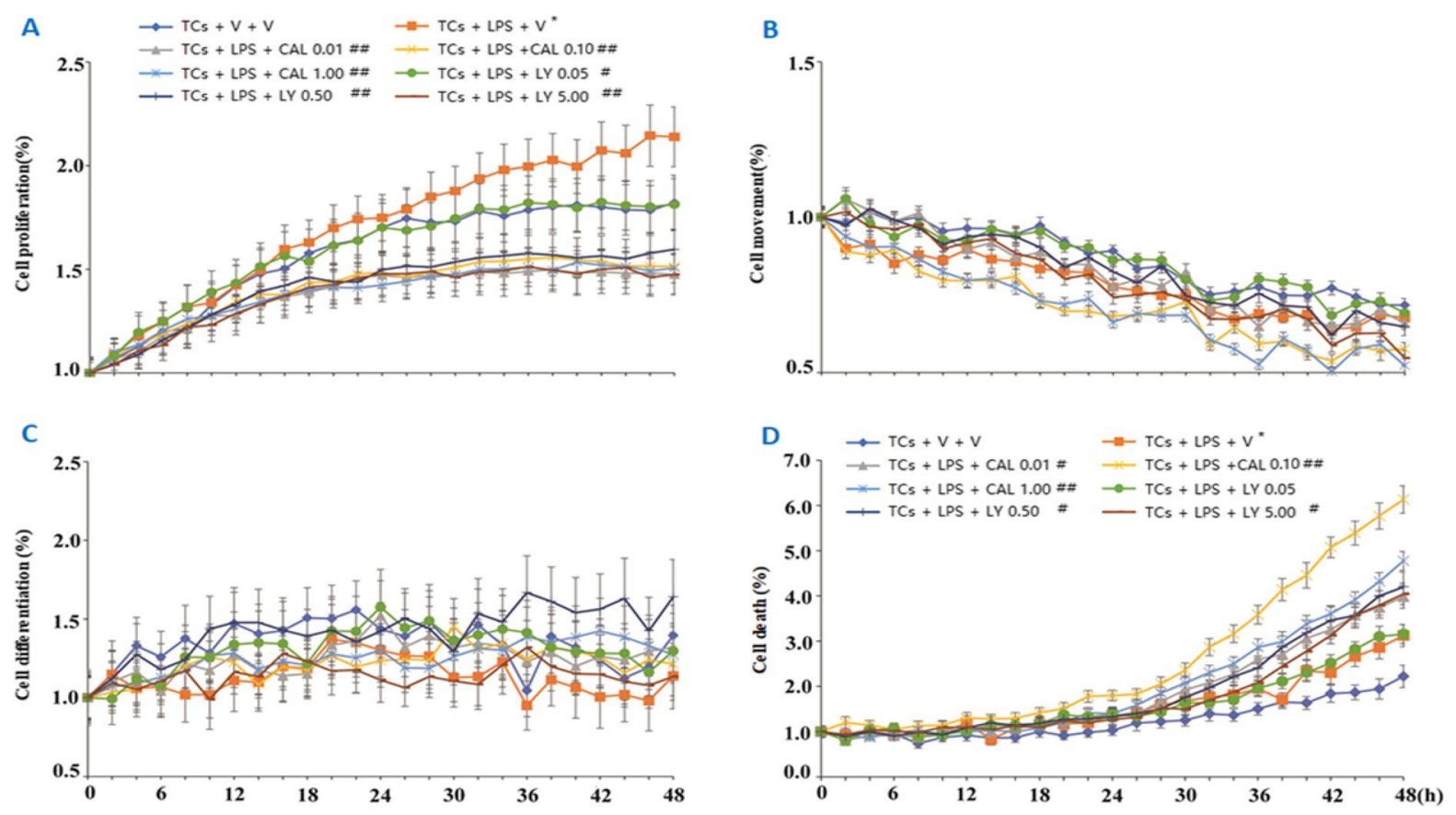

Fig. 2 Dynamic phenotype of mouse-derived TCs in response to PI3K inhibitors. Dynamic alterations of TC proliferation (A), movement (B), differentiation (C), and death (b) $48 \mathrm{~h}$ after

and differentiation (Fig. 2C), and increased the number of dead TCs (Fig. 2D), of which CAL at the dose of $0.1 \mu \mathrm{M}$ induced the highest number of dead TCs. In order to define potential responses of TCs per se to challenge and treatments, TCs were challenged with LPS and treated with CAL or LY, respectively (Figure S1C). The expression of Mtor, Hifl $\alpha$, Vegf$a$, or Mmp 9 mRNA increased in TCs challenged with LPS, while Mtor, Hifl $\alpha$, and Vegf-a even more increased after adding CAL (Fig. 3A) or Mtor after adding LY (Fig. 3B). The expression of $M m p 9$ mRNA down-regulated in TCs with LPS and CAL or LY. Protein expression of AKT, phosphorylated mTOR (p-mTOR), HIF1 $\alpha$, and VEGF-A significantly increased in LPS-challenged TCs, of which p-mTOR and $\mathrm{HIF} 1 \alpha$ reduced after adding CAL (Fig. 3C) or LY (Fig. 3D).

Influencing roles of TCs in HBE phenotype

Airway epithelial cells as the primary defense line act as the initial receptors in response to external antigens and as the secondary reactors to initiate the local and systemic inflammation. The present study investigates

challenge with vehicle (V) or with LPS and treatment with PI3K p1108 inhibitor (CAL) at $0.01,0.1$, and $1 \mu \mathrm{M}$ or with $\mathrm{PI} 3 \mathrm{~K} \alpha / \delta / \beta$ inhibitor (LY) at $0.05,0.5$, or $5 \mu \mathrm{M}$, respectively

whether TCs can influence airway epithelial cells in normal or inflammatory condition and what signal pathways may contribute to the interaction of TCs with epithelia. After the preliminary screening, we selected the ratio of TC cell density to HBE cell density as $1: 1$ and the co-cultivation time for $24 \mathrm{~h}$, which TCs in the upper layer of TCs can efficiently promote the proliferation of HBE in the lower layer of chamber measured by CCK8 (Figure S1B).

On basis of our previous studies that PI3K subunits play various roles in TC biology, we selected two of PI3K subunits, PI3K p1108, with the inhibitor of CAL-101, or PI $3 \mathrm{~K} \alpha / \delta / \beta$, with the inhibitor of LY294002. We found that the rate of epithelial cell proliferation was higher in co-culture of HBE and TCs (named "co-cultured HBE" here) than that in HBE alone (named "mono-cultured HBE") under conditions with or without LPS challenge $(p<0.05$; Fig. 4A) or when cells were treated with LPS and CAL at different doses $(p<0.05$; Fig. 4B) or LPS and $\mathrm{LY}$ at doses of 0.05 and $5 \mu \mathrm{M}(p<0.05$ and 0.01 , respectively; Fig. 4C). HBE differentiation rate was significantly higher in co-cultured $\operatorname{HBE}(p<0.01$, vs HBE alone; Fig. 4D), while the differentiation of 
co-cultured HBE did not show a significant difference from mono-cultured HBE treated with LPS alone or combined with CAL (Fig. 4E) or LY (Fig. 4F). HBE death significantly reduced in co-cultured HBE cells treated with vehicle (Fig. 4G) or treated with LPS and CAL (Fig. 4H) or LY (Fig. 4I), as compared with mono-cultured HBE. There was no statistical difference in dynamic HBE cell movements between mono- and co-cultured HBE cells (Figure S2F).

\section{Effects of TCs on HBE responses to PI3K inhibitors}

In order to define potential effects of TCs on HBE cells and the involvement of PI3K signal pathways, we performed mono-cultured HBE or non-contacted and co-cultured HBE with TCs in the condition with or without LPS (Figure S1D, E). We evaluated the decisive roles of $\mathrm{PI} 3 \mathrm{~K} p 110 \delta$ and $\mathrm{PI} 3 \mathrm{~K} \alpha / \delta / \beta$ in the interaction between TCs and HBE cells (Fig. 6F). Due to the high value of $M m p 9$ in HBE in RTqPCR, the gene expression is low, so the transcription level of Mmp9 is not shown here. We found that mRNA expression of Hifl $\alpha$ or Vegf-a significantly increased in mono-cultured (Fig. 5A) or co-cultured cells (Fig. 5B), challenged with LPS as compared with those with vehicle $(p<0.05$ or less, respectively). LY inhibited LPS-induced mRNA expression of Mtor, Hifl $\alpha$, or Vegf-a in mono-cultured HBE, and co-cultured HBE. CAL showed inhibitory effects on mRNA expression of Mtor, Hifl $\alpha$, or Vegf- $a$ in co-cultured HBE, rather than in monocultured HBE (Fig. 5A, B). Protein expression of p-AKT, mTOR, HIF1 $\alpha$, or VEGF-A in co-cultured HBE challenged with LPS was significantly higher than that with vehicle (Fig. 5C-F), which was not observed in mono-cultured HBE. Of those, protein levels of AKT, mTOR, and HIF1 $\alpha$ were significantly lower in co-cultured HBE cells treated with LPS and CAL, as compared with co-cultured HBE with LPS and vehicle or mono-cultured HBE with LPS and CAL (Fig. 5C, E). Mono- and co-cultured HBE had different patterns in response to LY; e.g., AKT and p-AKT increased and HIF $1 \alpha$ and MMP9 decreased in co-cultured HBE, as compared with those in mono-cultured HBE (Fig. 5D, F). LY inhibited VEGF-A contents in mono-cultured HBE in a clear LY dose-dependent pattern, rather than in cocultured HBE (Fig. 5D, F).
Roles of TC-derived exosomes in HBE functions

In addition to inflammatory factors and growth factors, the cell-derived exosomes have been proposed to play an important role in the process of cell-cell communication (Song et al., 2019b). We isolated exosomes from TCs challenged with LPS and treated with LY at $0.05,0.5$, and $5.0 \mu \mathrm{M}$ for $24 \mathrm{~h}$, purified TC-derived exosomes, and co-cultured HBE with labeled exosomes (Figure S1F). The exosomes were identified by ultrastructure (Fig. 6A) and surface protein markers (Fig. 6B). The exosome diameters were about $30-150 \mathrm{~nm}$, with membrane-based structures in some large exosomes. The protein expression of CD63 was clear and high, while CD9 was low. And TCderived exosomes do not express CD81. We furthermore co-cultured HBE with PKH26-labeled exosomes and monitored by a confocal microscope, and found that the majority of those LPS- and LYtreated exosomes surrounded closely HBE in the extracellular matrix and nuclei in the cytoplasm, while some appeared within the nuclei of $\mathrm{HBE}$ (Fig. 6C). The TC-derived exosomes per se could down-regulate the expression of HIF $1 \alpha$, p-AKT, and p-mTOR of HBE in the condition of non-challenge and treatments (Fig. 6D, E). The expression of AKT, p-AKT, HIF $1 \alpha$, and VEGF-A protein of HBE was increased after co-cultured with LPSpretreated exosomes, as compared with co-cultured HBE with vehicle-pretreated exosomes $(p<0.05$ or less, respectively; Fig. 6D, E). LY-pretreated exosomes had inhibited effects of exosomes on those protein expression levels depending on doses and markers.

\section{Discussion}

TCs are known as an alternative of cell therapies for organ tissue injury and repair, dysfunction, and failure through the comprehensive connections with other cells (Wang \& Cretoiu, 2016; Ibba-Manneschi et al., 2016; Bei et al., 2016). Zhang et al. (2020) found that inhibition rates of TCs, MSCs, or combination for ALI were $20 \%, 40 \%$, or $70 \%$, respectively, dependent upon cell doses and quality, transplant approaches, and time, as well as injury severities and duration after LPS induction. In addition, the medium 


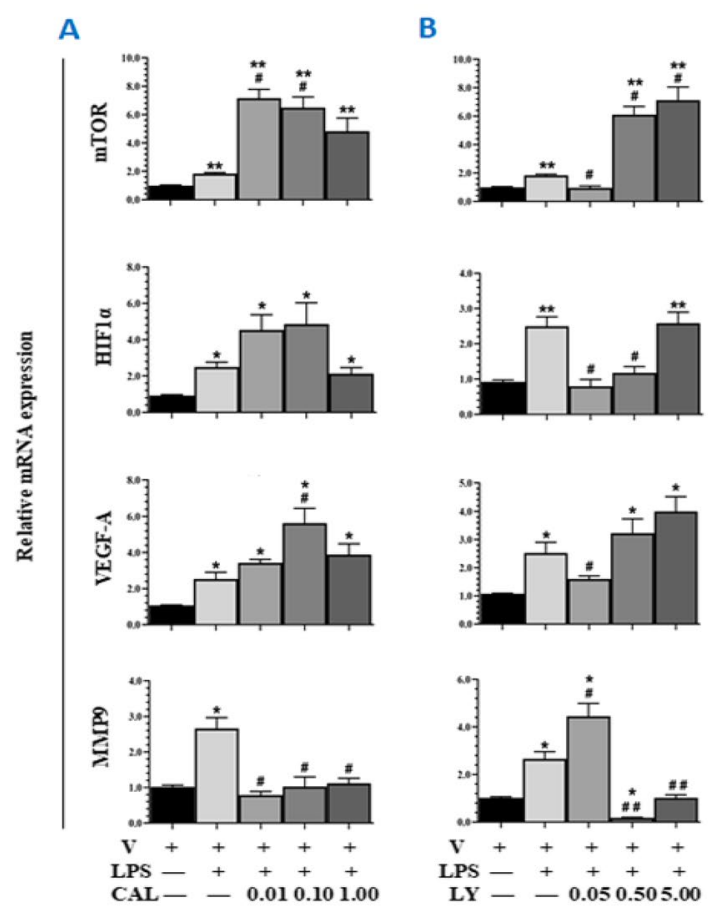

Fig. 3 Responses of TCs to challenge. TCs were challenged with vehicle (V) or LPS and treated with PI3K p1108 inhibitor (CAL) at $0.01,0.1$, and $1 \mu \mathrm{M}$ or with $\mathrm{PI} 3 \mathrm{~K} \alpha / \delta / \beta$ inhibitor (LY) at $0.05,0.5$, or $5 \mu \mathrm{M}$, respectively. mRNA expression of Mtor, Hifl $\alpha$, Vegf- $a$, and Mmp9 of TCs challenged with LPS and treated with CAL at $0.01,0.1$, and $1.0 \mu \mathrm{M}$ (A) or LY at

produced from TCs, MSCs, or combination activated by LPS could reduce the severity of ALI. It was evidenced that TCs could increase MSC migration from peritoneal space into lung tissue and reside with MSCs together as the cell niche or in neighbor of MSCs within the lung, indicating the importance of TC-MSC interaction and intercellular communication through cell-produced medium (Song et al., 2019b). MSC administration attenuates sepsis-induced lung injury in pre-clinical models (Santos et al., 2021). MSCs and MSC-derived secretome had been demonstrated to have great potential for ARDS treatment in COVID-19 patients (Chouw et al., 2021). However, the mechanisms had been unclear. Studies on the intratracheal instillation of TC culture medium in animals with ALI/ARDS furthermore demonstrated that the products from TCs reduced LPSinduced lung inflammation and injury by activating endothelial cells, initiating angiogenetic process, and
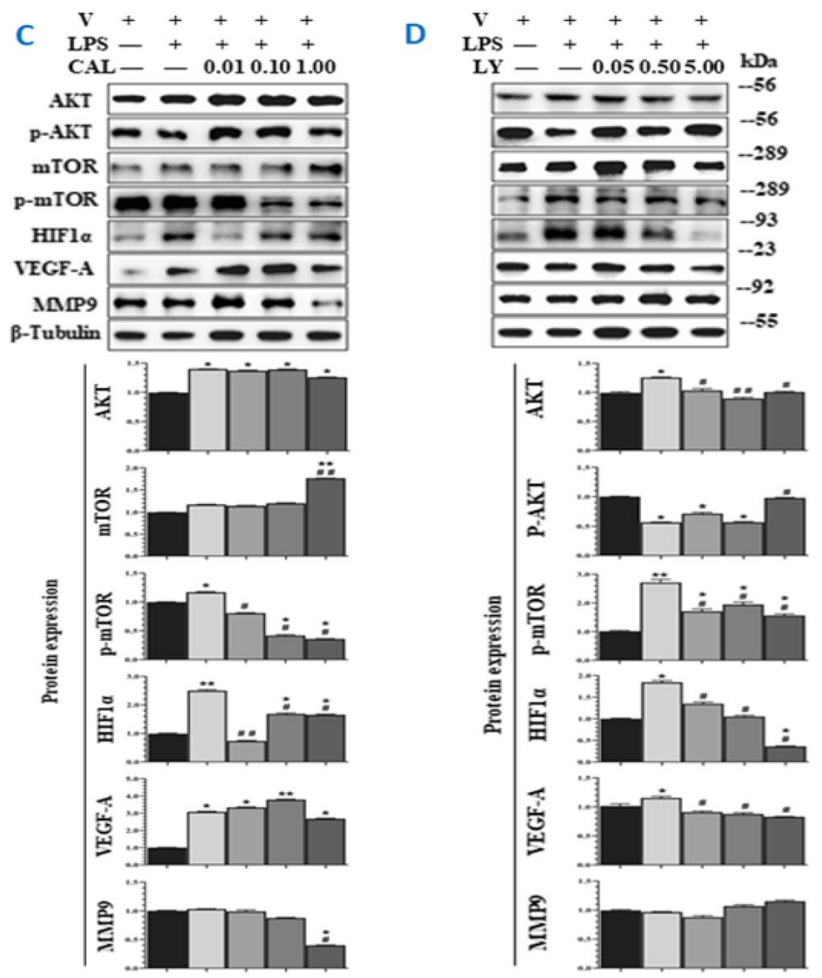

$0.05,0.5$, and $5.0 \mu \mathrm{M}(\mathbf{B})$. Protein expression of AKT, p-AKT, mTOR, p-mTOR, VEGF-A, and MMP9 of TCs challenged with LPS and treated with CAL at $0.01,0.1$, and $1.0 \mu \mathrm{M}(\mathbf{C})$ or $\mathrm{LY}$ at $0.05,0.5$, and $5.0 \mu \mathrm{M}$ (D). The upper bands in $\mathbf{C}$ and $\mathbf{D}$ are WB bands, and lower is the result of quantitative analysis of WB bands

maintaining endothelial barrier function through regulations of miR-21a-3p, production of VEGF-A, and activation of PI3K p110 $\alpha$ signal (Zhou et al., 2019). TCs per se also have beneficial effects on mechanical ventilation-induced lung tissue inflammation, injury, or lung function, and could promote the proliferation of pulmonary vascular endothelial cells by VEGF-A from TCs (Ma et al., 2018). The present study provides evidence that TCs interact with airway epithelial cells directly and indirectly through multiple factors and exosomes from activated TCs. Intraperitoneal transplantation of TCs could partially ameliorate the severity of experimental ALI and prevent from lung epithelial cell injury through the production of VEGF-A. As a type of interstitial cell, the functions of fibroblast, L929, were found to be positive in the $24 \mathrm{~h}$ of LPS-induced mice models. Fibroblast had almost been studied in the fibrotic remodeling and persistent reduced oxygenation in some patients 

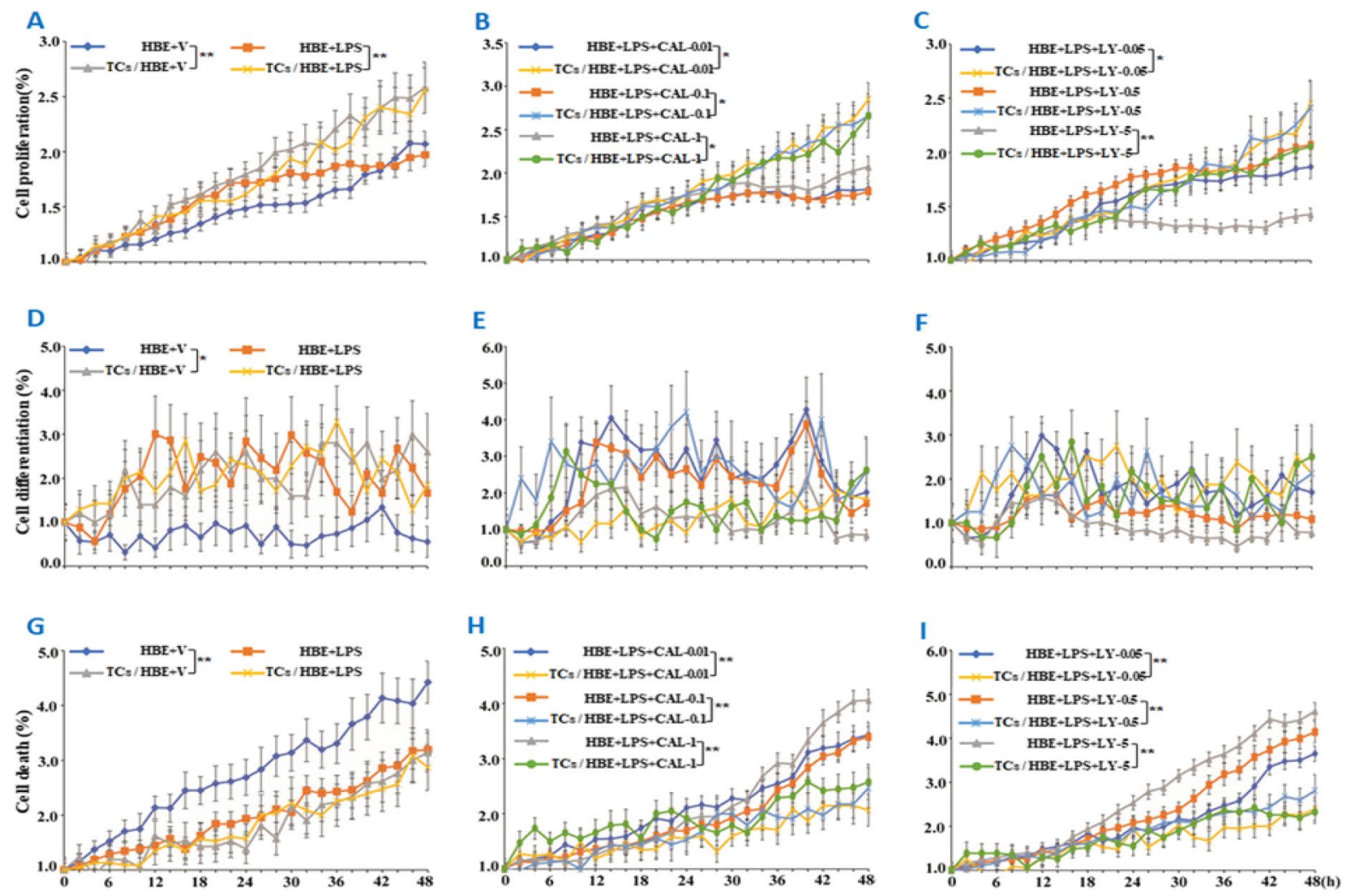

Fig. 4 Influencing roles of TCs in HBE phenotype. Dynamic alterations of $\mathrm{HBE}$ cell proliferation $(\mathbf{A}-\mathbf{C})$, differentiation (D-F), and death $(\mathbf{G}-\mathbf{I})$ were monitored using the Cell-IQ alive system in mono-cultured (HBE) or co-cultured HBE cells (TCs/HBE) challenged with vehicle (V) or LPS at $1 \mu \mathrm{g} / \mathrm{mL}$

followed by ARDS. Uncontrolled fibroblast proliferation and the deposition of collagen and extracellular matrix (ECM) proteins were involved in this process (Kiener et al., 2021).

Multiple factors from TCs play the critical roles in regulation of epithelial cell function. Zheng et al. (2014b) demonstrated that the amount of VEGF-A in TCs 24 and $48 \mathrm{~h}$ after the culture was more than 10 folds higher than that of others like tumor necrosis factor- $\alpha$, interferon- $\gamma$, granulocyte-macrophage colony-stimulating factor, monocyte chemotactic protein 1 , and tissue inhibitor of matrix metalloproteinases, responsible for the induction of angiogenesis and endothelial cell proliferation. In the International Mouse Strain Resource, more than 286,000 strains are listed, but only 883 are designated as inbred strains or major histocompatibility (www.findmice.
(A, D, and $\mathbf{G})$, pretreated with PI3K p1108 inhibitor (CAL) at $0.01,0.1$, and $1 \mu \mathrm{M}(\mathbf{B}, \mathbf{E}$, and $\mathbf{H})$, or pretreated with $\mathrm{PI} 3 \mathrm{~K} \alpha /$ $\delta / \beta$ inhibitor (LY) at $0.05,0.5$, or $5 \mu \mathrm{M}(\mathbf{C}, \mathbf{F}$, and $\mathbf{I}) . *$ and $* *$ stand for $p$ values less than 0.05 and 0.01 , as compared with HBE cells pretreated and challenged with vehicle, respectively

org). The current study selected mice of the inbred line BALB/c, and C57BL/6. The TCs in this study were derived from $B A L B / c$ mice. Our data showed that TCs had a significant effect to prevent LPSinduced ALI as accompanied with an increased level of VEGF-A in lung tissue, different from fibroblasts, although TCs and fibroblasts showed some similar protective effects on some measurement. It seems that TCs mainly prevented LPS-induced lung endothelial cell barrier dysfunction evidenced by reduced histological tissue edema, cytokine leaks from the interstitial tissue and capillaries, and tissue water content. We found that levels of multiple factors increased and believe the mechanism of TC protection more comprehensive. For example, TCs also have high levels of epidermal growth factor (Zheng et al., 2014b) and platelet-derived growth factor receptor- $\beta$ (Suciu et al., 

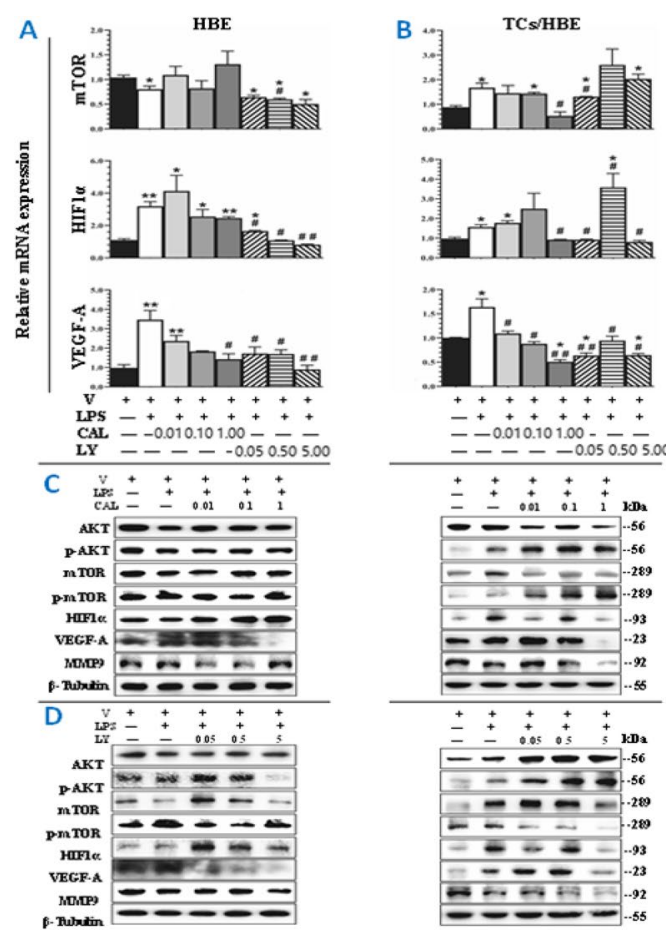

Fig. 5 Potential factors and PI3K signals involved in the interaction between TCs and HBE. HBE cells were cultured with or without TCs challenged with vehicle (V) or LPS and treated with PI3K p1108 inhibitor (CAL) at $0.01,0.1$, and $1 \mu \mathrm{M}$ or with $\mathrm{PI} 3 \mathrm{~K} \alpha / \delta / \beta$ inhibitor (LY) at $0.05,0.5$, or $5 \mu \mathrm{M}$. A, B mRNA expression of Mtor, Hifl $\alpha$, and Vegf- $a$ in mono-cultured HBE (HBE) and co-cultured HBE (TCs/HBE). mRNA expression of Mtor, Hifl $\alpha$, or Vegf- $a$ in co-cultured HBE was decreased with the treatment of CAL, rather than in monocultured HBE ( $p$ values less than 0.05 and 0.01). C-F Pro-

2012). Our previous study demonstrated that a large number of transcriptional factors were altered in TCs after LPS stimulation, of which six clusters and networks were suggested to play the critical roles in control and regulation of TC responses to LPS (Zhang et al., 2020). TGF $\beta 1$ and IL-10 were immune factors with the function of immune hyper-response inhibition. Levels of TGF $\beta 1$ were found to be increased in ovalbumin-provoked mice asthma models with the treatment of TCs or MSCs which indicated that TCs may have the ability in immune regulation (Ye et al., 2017). Thus, the increase of IL-10 levels, although without significance, in TC-treated LPS-induced ALI models in our current study might be because of the immune regulation of TCs.

Responses of TCs to inflammation vary among the severities, pathogens, doses, and durations. Our

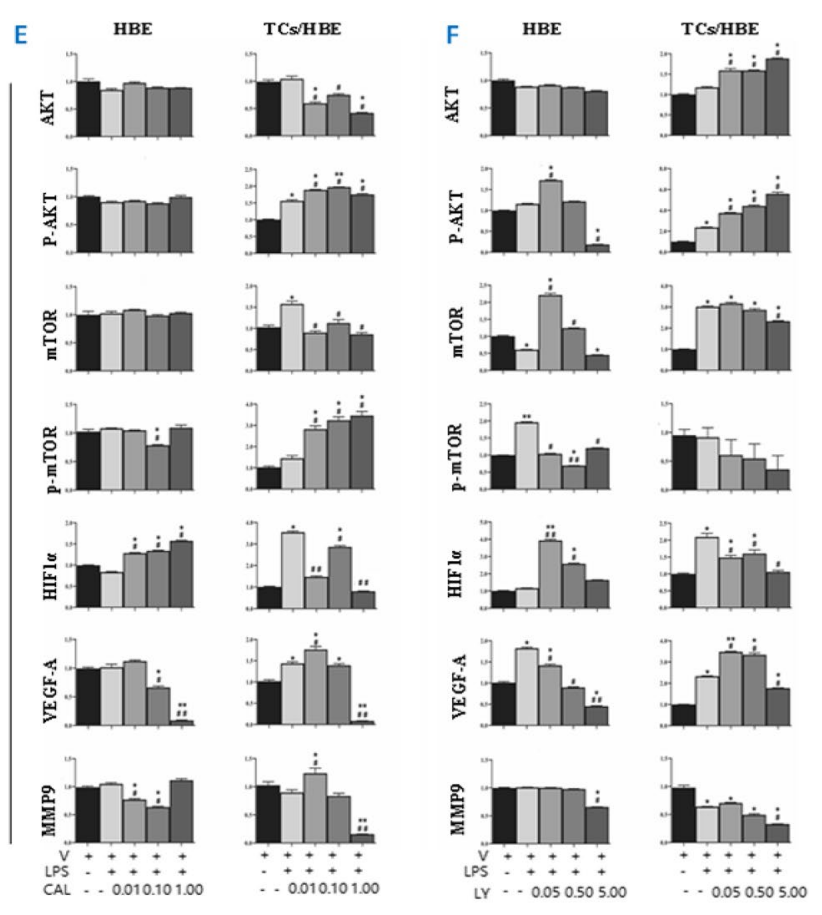

tein expression and levels of AKT, p-AKT, mTOR, p-mTOR, HIF1 $\alpha$, VEGF-A, and MMP9 A in mono-cultured HBE (HBE) and co-cultured HBE (TCs/HBE). The bands in $\mathbf{C}$ and $\mathbf{D}$ are WB bands. $\mathbf{E}$ and $\mathbf{F}$ are the result of quantitative analysis of WB bands. * and ** stand for $p$ values less than 0.05 and 0.01 , as compared with cells pretreated and challenged with vehicle (V), while \# and \# \# stand for $p$ values less than 0.05 and 0.01 , as compared with cells pretreated with vehicle and challenged with LPS (LPS), respectively

previous studies have verified that PI3K p1 $10 \delta$ inhibitor (CAL101) and PI3K $\alpha / \delta / \beta$ inhibitor (LY294002) can affect the biological behavior of TCs such as proliferation, and our present data demonstrated that PI3K $\mathrm{p} 110 \delta$ and $\alpha / \delta / \beta$ isoforms played important roles in TC responses to LPS. Our previous study presented one of mechanisms by which networks and interactions of $\mathrm{PI} 3 \mathrm{~K} \alpha / \delta / \beta$, PI $3 \mathrm{~K} / \mathrm{mTOR}$, and PI3K p1108 isoform proteins with TGF $\beta$ family proteins contributed to the proliferation of lung telocytes (Song et al., 2020). Of those PI3K isoforms, the expression of $\mathrm{PI} 3 \mathrm{~K} \alpha / \delta / \beta$ was more sensitive during

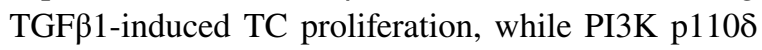
upregulated TC proliferation and movement independently and down-regulated in a TGF $\beta 1$-dependent pattern. Our previous study addressed the molecular mechanism by which the cell cycle and proliferation 
A

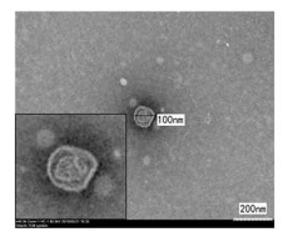

B

C

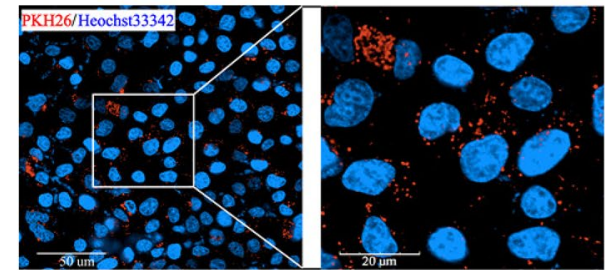

D

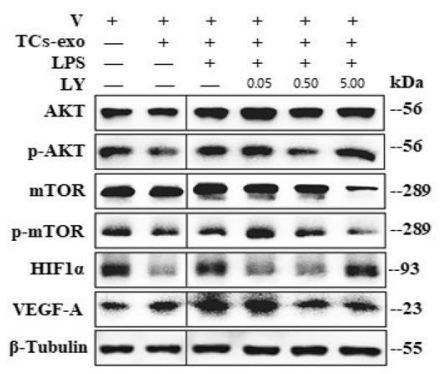

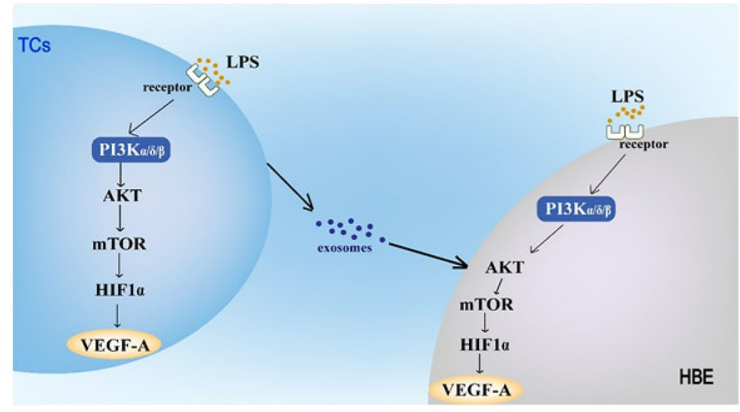


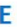
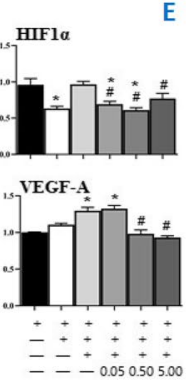

Fig. 6 Roles of TC-derived exosomes in HBE response. The ultrastructure of exosomes was identified (A) using TEM $(40,000 \times)$ and CD81, CD61, and CD9 of exosomes were measured by Western blot (B). The distributions of PKH26labeled exosomes were monitored with a confocal microscope $(63 \times$ water mirror) (C). Expression of AKT, p-AKT, mTOR, p-mTOR, HIF1 $\alpha$, VEGF-A, and MMP9 protein was assayed (D and $\mathbf{E}$ ). The bands in $\mathbf{D}$ are WB bands. The result of quan- titative analysis of WB bands is shown in E. Potential mechanisms were proposed to be responsible for the intercellular communication $(\mathbf{F})$. * and $* *$ stand for $p$ values less than 0.05 and 0.01 , as compared with HBE pretreated and challenged with vehicle $(\mathrm{V})$, while \# and \# \# stand for $p$ values less than 0.05 and 0.01 , as compared with cells pretreated with vehicle and challenged with LPS + TCs-exo, respectively

local stem cell proliferation and epithelial renewal (Shoshkes-Carmel et al., 2018). The Wnt/betacatenin signaling is activated via the PI3K/Akt pathway (Tomar et al., 2020). TCs could form networks with Tps under and along with the intestinal epithelial layer and deliver the messages through the Wnt signal pathway. Lgr5-positive TCs within spatially zonated populations were detected by combining laser capture micro-dissection and single cell RNA sequencing, to line the villus tip epithelium and signal through Bmp morphogens and the non-canonical Wnt5a ligand (Bahar Halpern et al., 2020). TC was proposed as an important regulator of the epithelial spatial expression programs along the villus axis. Although the close interaction between TCs and epithelial cells was suggested previously, there is a lack of direct evidence to show effects of TCs on epithelial bio-behaviors and functions. We showed the evidence that TCs could nourish airway epithelial cells through nutrients produced from 
TCs, rather than the message delivered through the direct connection/contract between TCs and epithelia. During the co-culture, TCs increased epithelial cell proliferation and differentiation and decreased the number of epithelial cell death.

TCs increased epithelial cell sensitivity to LPS challenge as well as against PI3K p110 $\delta$ and $\alpha / \delta / \beta$ inhibitors, although the exact molecular mechanisms remain unclear. PI3K signaling pathway plays the important role in the regulation of cell responses to drugs (Sabnam and Pal, 2019). It seems that TCs can improve the capacity of epithelial cell bio-behaviors and functions during cell-cell interactions and the sensitivity of epithelia to pathogens or drugs in a non-specific pattern. Our present data indicate that TCs interact with epithelial cells and improve epithelial bio-behaviors through altered expression of phosphorylated AKT and VEGF-A in response to PI3K $110 \delta$ and $\alpha / \delta / \beta$ isoforms, $\mathrm{p}$-mTOR to PI3K $\mathrm{p} 110 \delta$ isoform, and mTOR and $\mathrm{HIF} 1 \alpha$ to $\mathrm{PI} 3 \mathrm{~K} \alpha / \delta / \beta$ isoform, rather than the influence mRNA expression of considered genes, although the exact molecular mechanisms remain unclear. In addition to products from TCs, PI3K isoforms can be activated by Tyr kinases, G protein-coupled receptors, Ras, and other regulators, to control the trafficking of intracellular vesicles and release exosomes in the context of autophagy, endocytosis, and phagocytosis (Vanhaesebroeck et al., 2010).

Exosomes driven from TCs play an important role in nutrimental effects of TCs on airway epithelial cell bio-behaviors. Exosomes about 40-150 nm together with nucleosomes and microvesicles about $150-1000 \mathrm{~nm}$ as well as particles constitute extracellular vesicles, with a large variation of sizes, components, origins, and functions. Transmembrane proteins, including CD63, CD81, and CD9, have been reported to be expressed on the surface and as classic markers of exosomes. Since there are no specific markers on TC exosomes, it is difficult to sort TC-specific exosomes from other exosomes in blood sample. Exosomes contain mRNA, miRNA, and other non-coding RNA, DNA, proteins, and lipids. Of those, heavily glycosylated proteins of exosomes are also considered one of the main elements responsible for exosome biosynthesis and function (Lin et al., 2020). With the development of models for reassessment of exosome composition, the heterogeneity of extracellular vesicles was furthermore understood to discover the compartment and mechanisms in human disease (Jeppesen et al., 2019). It was proposed that exosomes may change cell sensitivity to drugs through transporting its rich contents, as a potential mechanism of exosome-mediated drug resistance and therapeutic potential for diseases ( $\mathrm{Li}$ et al., 2020b). This is the first try to isolate and purify exosomes from lung TCs, on basis of the experience as the first group to isolate and purify TCs from human airway (Zheng et al., 2011). Due to the morphological characteristics of TCs with small cell body and contents, long and thin Tps, and rich mitochondria, the difficulty of exosome isolation from TCs was more than from other cells. Our data demonstrated that TC-driven exosomes could directly influence the expression of those target genes, similar to effects of TCs. Molecular mechanisms of TC-driven exosomes on airway epithelial cells remain unclear, although exosomes in other cells were found to be a cargo of lncRNA, microRNA, or nutrients for cell differentiation, regeneration, and repair (Yan and $\mathrm{Wu}, 2020$; Chang et al., 2021). The evidence of the role of exosomes and the role of PI3K pathway and inhibitors on exosomes needs to be more deeply studied in vivo.

In conclusion, the present study demonstrated that intraperitoneal administration of TCs ameliorated the severity of lung tissue edema accompanied by elevated expression of VEGF-A. PI3K $110 \delta$ and $\alpha / \delta / \beta$ isoforms are involved in LPS-induced activation of TCs with alterations of mRNA expression of Mtor, Hifl $\alpha$, Vegf-a, and Mmp9 in TCs. TCs could nourish airway epithelial cells through nutrients produced from TCs, increasing epithelial cell proliferation and differentiation as well as cell sensitivity to LPS challenge and PI3K p110 $\delta$ and $\alpha / \delta / \beta$ inhibitors, partially through exosomes released from TCs. Thus, our data indicate that products from TCs may be an alternative of potential therapies for ALI/ARDS. Furthermore, the role of VEGF-A production is very speculative which has the value of further study.

Author contribution LT and DS designed the study and completed the experimental process, literature search, and generation of figures. XW and DS wrote and edited the manuscript. LT, XW, DS, and RQ completed generation of figures. BJ provided the experimental technical and laboratory facility support. All authors reviewed the manuscript. All authors read 
and approved the final manuscript. Corresponding authors Corresponding to: Dongli Song or Xiangdong Wang

Funding The work was supported by Zhongshan Distinguished Professor Grant (XDW), the National Nature Science Foundation of China (81873409, 81700008, 91230204, 81270099, 81320108001, 81270131, 81300010), Original Research Personalized Support Project of Fudan University (IDF152064/011), the Shanghai Committee of Science and Technology (12JC1402200, 12431900207, 11410708600, 14431905100, 21140902601, 21140902600), Operation Funding of Shanghai Institute of Clinical Bioinformatics, Ministry of Education for Academic Special Science and Research Foundation for PhD Education (20130071110043), and National Key Research and Development Program (2016YFC0902400, 2017YFSF090207, 2017YFC0909500), Shanghai Engineering Research Center of Tumor Multi-Target Gene Diagnosis (20DZ2254300), and Key Subject Construction Program of Shanghai Health Administrative Authority (ZK2019B30).

\section{Availability of data and materials Not applicable.}

\section{Declarations}

Consent of publication All the work reported in the manuscript is original and has not yet been submitted in other journal. Authors agree to transfer the copyright of manuscript to the Applied Biochemistry and Biotechnology Journal upon acceptance for publication.

Conflict of interest The authors declare no competing interests.

\section{References}

Aleksandrovych V, Kurnik-Łucka M, Bereza T, et al. The autonomic innervation and uterine telocyte interplay in leiomyoma formation. Cell Transplant. 2019;28(5):619-29.

Alm AS, Li K, Chen H, Wang D, Andersson R, Wang X. Variation of lipopolysaccharide-induced acute lung injury in eight strains of mice. Respir Physiol Neurobiol. 2010;171(2):157-64.

Chouw A, Milanda T, Sartika CR, Kirana MN, Halim D, Faried A. Potency of mesenchymal stem cell and its secretome in treating COVID-19. Regen Eng Transl Med. 2021;1-12. https://doi.org/10.1007/ s40883-021-00202-5.

Bahar Halpern K, Massalha H, Zwick RK, Moor AE, Castillo-Azofeifa D, Rozenberg M, et al. Lgr5+ telocytes are a signaling source at the intestinal villus tip. Nat Commun. 2020;11(1):1936. https://doi.org/10.1038/ s41467-020-15714-X.

Bei Y, Zhou Q, Sun Q, Xiao J. Telocytes in cardiac regeneration and repair. Semin Cell Dev Biol. 2016;55:14-21. https://doi.org/10.1016/j.semcdb.2016.01.037.
Bilanges B, Posor Y, Vanhaesebroeck B. PI3K isoforms in cell signalling and vesicle trafficking. Nat Rev Mol Cell Biol. 2019;20(9):515-34.

Chang J, Li H, Zhu Z, Mei P, Hu W, Xiong X, Tao J. microRNA-21-5p from M2 macrophage-derived extracellular vesicles promotes the differentiation and activity of pancreatic cancer stem cells by mediating KLF3. Cell Biol Toxicol. 2021. https://doi.org/10.1007/ s10565-021-09597-X

Chen H, Bai C, Wang X. The value of the lipopolysaccharideinduced acute lung injury model in respiratory medicine. Expert Rev Respir Med. 2010;4(6):773-83.

Claudia C Dos Santos, Hajera Amatullah, Chirag M Vaswani, Tatiana Maron-Gutierrez, Michael Kim, Shirley H J Mei, Katalin Szaszi, Ana Paula T Monteiro, Amir K Varkouhi, Raquel Herreroz, Jose Angel Lorente, James N Tsoporis, Sahil Gupta, Amin Ektesabi, Nikolaos Kavantzas, Vasileios Salpeas, John C Marshall, Patricia R M Rocco, Philip A Marsden, Daniel J Weiss, Duncan J Stewart, Pingzhao Hu, W Conrad Liles. Mesenchymal stromal (stem) cell (MSC) therapy modulates miR-193b-5p expression to attenuate sepsis-induced acute lung injury. Eur Respir J. 2021;2004216. doi: https://doi.org/10.1183/ 13993003.04216-2020.

Ding Z, Zhong R, Yang Y, Xia T, Wang W, Wang Y, et al. Systems pharmacology reveals the mechanism of activity of Ge-Gen-Qin-Lian decoction against LPS-induced acute lung injury: a novel strategy for exploring active components and effective mechanism of TCM formulae. Pharmacol Res. 2020;156:104759.

Fang XC, Bai CX, Wang X. Bioinformatics insights into acute lung injury/acute respiratory distress syndrome. Clin Transl Med. 2012;1(1):9.

Faussone-Pellegrini MS, Gherghiceanu M. Telocyte's contacts. Semin Cell Dev Biol. 2016;55(9):3-8.

He Z, Zhu Y, Jiang H. Toll-like receptor 4 mediates lipopolysaccharide-induced collagen secretion by phosphoinositide3-kinase-Akt pathway in fibroblasts during acute lung injury. J Recept Signal Transduct Res. 2009;29(2):119-25.

Ibba-Manneschi L, Rosa I, Manetti M. Telocytes in chronic inflammatory and fibrotic diseases. Adv Exp Med Biol. 2016;913:51-76. https://doi.org/10.1007/ 978-981-10-1061-3_4.

Jansson AH, Smailagic A, Andersson AM, et al. Evaluation of excised lung gas volume measurements in animals with genetic or induced emphysema. Respir Physiol Neurobiol. 2006;150(2-3):240-50.

Jeppesen DK, Fenix AM, Franklin JL, Higginbotham JN, Zhang Q, Zimmerman LJ, et al. Reassessment of exosome composition. Cell. 2019;177(2):428-445.e18. https://doi. org/10.1016/j.cell.2019.02.029.

Kim DI, Kim SR, Kim HJ, Lee SJ, Lee HB, Park SJ, et al. $\mathrm{PI} 3 \mathrm{~K}-\gamma$ inhibition ameliorates acute lung injury through regulation of $\mathrm{I} \kappa \mathrm{B} \alpha / \mathrm{NF}-\kappa \mathrm{B}$ pathway and innate immune responses. J Clin Immunol. 2012;32(2):340-51.

Li L, Huang Q, Wang DC, Ingbar DH, Wang X. Acute lung injury in patients with COVID-19 infection. Clin Transl Med. 2020;10(1):20-7. https://doi.org/10.1002/ctm2.16.

Li S, Yi M, Dong B, Jiao Y, Luo S, Wu K. The roles of exosomes in cancer drug resistance and its therapeutic 
application. Clin Transl Med. 2020;10(8):e257. https:// doi.org/10.1002/ctm2.257.

Lin S, Zhou S, Yuan T. The, "sugar-coated bullets" of cancer: tumor-derived exosome surface glycosylation from basic knowledge to applications. Clin Transl Med. 2020;10(6):e204. https://doi.org/10.1002/ctm2.204.

Ma R, Wu P, Shi Q, Song D, Fang H. Telocytes promote VEGF expression and alleviate ventilator-induced lung injury in mice. Acta Biochim Biophys Sin (shanghai). 2018;50(8):817-25. https://doi.org/10.1093/abbs/gmy066.

Kiener M, Roldan N, Machahua C, Sengupta A, Geiser T, Guenat OT, Funke-Chambour M, Hobi N, Kruithof-de Julio M. Human-based advanced in vitro approaches to investigate lung fibrosis and pulmonary effects of COVID19. Front Med (Lausanne). 2021;8:644678. https://doi. org/10.3389/fmed.2021.644678.

Popescu LM, Gherghiceanu M, Suciu LC, Manole CG, Hinescu ME. Telocytes and putative stem cells in the lungs: electron microscopy, electron tomography and laser scanning microscopy. Cell Tissue Res. 2011;345(3):391-403.

Sabnam S, Pal A. Relevance of Erk1/2-PI3K/Akt signaling pathway in CEES-induced oxidative stress regulates inflammation and apoptosis in keratinocytes. Cell Biol Toxicol. 2019;35(6):541-64. https://doi.org/10.1007/ s10565-019-09467-7.

Shoshkes-Carmel M, Wang YJ, Wangensteen KJ, Tóth B, Kondo A, Massasa EE, Itzkovitz S, Kaestner KH. Subepithelial telocytes are an important source of Wnts that supports intestinal crypts. Nature. 2018;557(7704):242-6. https://doi.org/10.1038/s41586-018-0084-4.

Suciu LC, Popescu BO, Kostin S, Popescu LM. Platelet-derived growth factor receptor-beta-positive telocytes in skeletal muscle interstitium. J Cell Mol Med. 2012;16(4):701-7. https://doi.org/10.1111/j.1582-4934.2011.01505.x.

Song D, Xu M, Qi R, et al. Influence of gene modification in biological behaviors and responses of mouse lung telocytes to inflammation. J Transl Med. 2019;17(1):158.

Song D, Tang L, Wang L, et al. Roles of TGF $\beta 1$ in the expression of phosphoinositide 3-kinase isoform genes and sensitivity and response of lung telocytes to PI3K inhibitors. Cell Biol Toxicol. 2020;36(1):51-64.

Song D, Yang D, Powell CA, Wang X. Cell-cell communication: old mystery and new opportunity. Cell Biol Toxicol. 2019;35(2):89-93.

Sun X, Zheng M, Zhang M, Qian M, Zheng Y, Li M, Cretoiu D, Chen C, Chen L, Popescu LM, Wang X. Differences in the expression of chromosome 1 genes between lung telocytes and other cells: mesenchymal stem cells, fibroblasts, alveolar type II cells, airway epithelial cells and lymphocytes. J Cell Mol Med. 2014;18(5):801-10.

Tomar VS, Patil V, Somasundaram K. Temozolomide induces activation of $\mathrm{Wnt} /$ beta-catenin signaling in glioma cells via PI3K/Akt pathway: implications in glioma therapy. Cell Biol Toxicol. 2020;36(3):273-8. https://doi.org/10. 1007/s10565-019-09502-7.

Vanhaesebroeck B, Guillermet-Guibert J, Graupera M, Bilanges B. The emerging mechanisms of isoformspecific PI3K signalling. Nature Rev Mol Cell Biol. 2010;11:329-41.
Wang X, Adler KB, Erjefalt J, Bai CB. Role of airway epithelial dysfunction in development of acute lung injury and acute respiratory distress syndrome. Expert Rev Respir Med. 2007;1(1):149-55.

Wang X, Cretoiu D. Telocytes: connecting cells. Series Title: Advances in Experimental Medicine and Biology, Volume 913, Published by Springer Singapore, 2016.

Wollheim FA. Telocytes, communicators in healthy stroma and relation to inflammation and fibrosis. Joint Bone Spine. 2016;83(6):615-8.

Yan L, Wu X. Exosomes produced from 3D cultures of umbilical cord mesenchymal stem cells in a hollow-fiber bioreactor show improved osteochondral regeneration activity. Cell Biol Toxicol. 2020;36(2):165-78. https://doi.org/10. 1007/s10565-019-09504-5.

Ye L, Song D, Jin M, Wang X. Therapeutic roles of telocytes in OVA-induced acute asthma in mice. J Cell Mol Med. 2017;21(11):2863-71. https://doi.org/10.1111/jcmm. 13199.

Zhang D, Song D, Shi L, Sun X, Zheng Y, Zeng Y, Wang X. Mechanisms of interactions between lung-origin telocytes and mesenchymal stem cells to treat experimental acute lung injury. Clin Transl Med. 2020;10(8):e231. https:// doi.org/10.1002/ctm2.231.

Zhang L, Huang Q, Wang DC, Wang X. Significance of clinical phenomes of patients with COVID-19 infection: a learning from 3795 patients in 80 reports. Clin Trans1 Med. 2020;10(1):28-35. https://doi.org/10.1002/ctm2.17.

Zhenga Y, Cretoiu D, Yan G, Cretoiu SM, Popescu LM, Wang X. Comparative proteomic analysis of human lung telocytes with fibroblasts. J Cell Mol Med. 2014;18(4):568-89.

Zhengb Y, Chen X, Qian M, Zhang M, Zhang D, Bai C, Wang Q, Wang X. Human lung telocytes could promote the proliferation and angiogenesis of human pulmonary microvascular endothelial cells in vitro. Mol Cell Ther. 2014;1(2):3. https://doi.org/10.1186/2052-8426-2-3.

Zheng YH, Li H, Manole CG, Sun A, Ge J, Wang X. Telocytes in the trachea and lungs. J Cell Mol Med. 2011;15(10):2262-8.

Zheng Y, Zhang M, Qian M, et al. Genetic comparison of mouse lung telocytes with mesenchymal stem cells and fibroblasts. J Cell Mol Med. 2013;17(4):567-77.

Zhou Y, Yang Y, Liang T, Hu Y, Tang H, Song D, Fang H. The regulatory effect of microRNA-21a-3p on the promotion of telocyte angiogenesis mediated by PI3K (p110alpha)/AKT/mTOR in LPS induced mice ARDS. J Transl Med. 2019;17(1):427. https://doi.org/10.1186/ s12967-019-02168-z.

Publisher's note Springer Nature remains neutral with regard to jurisdictional claims in published maps and institutional affiliations. 